DOI 10.37882/2223-2982.2020.11.08

\title{
ДИАЛОГИЧЕСКАЯ РЕЧЬ В РАЗВИТИИ КОММУНИКАТИВНОЙ КОМПЕТЕНЦИИ НА ЗАНЯТИЯХ ИНОСТРАННЫМ ЯЗЫКОМ
}

\section{DIALOGIC SPEECH IN THE DEVELOPMENT OF COMMUNICATIVE COMPETENCE IN FOREIGN LANGUAGE CLASSES}

\section{A. Verhovod}

Summary: This paper examines dialogic speech and its impact on the development of communicative competence in foreign language classes. It is noted that dialogic speech in foreign language classes is one of the main tasks of forming communicative competence. At the moment, working on a dialogue in a foreign language is the most important methodological task, which is proved by a large number of articles and studies considered as a theoretical basis for writing the work. The article analyzes both the concept of dialogic speech, which is understood as the process of communication in which the replicas of two or more persons replace each other, and its main characteristics. The author specifies the main types of dialogue when learning a foreign language, and their topics can be provided by the program and include professional issues. It is concluded that dialogue replicas are not only questions and answers, but they can be described more precisely as a combination of requesting information and receiving it. In dialogical communication, internal acceptance of opponents and orientation to the individuality of each of them is important. Therefore, the article focuses on the factors that contribute to the positive learning of dialogic speech, one of which is the favorable relationship between the student and the teacher. For a teacher, an important aspect of dialogical communication with a student is the ability to consider him as an equal partner.

Keywords: foreign language, dialogic speech, dialogic communication, communicative competence.

\author{
Верховод Александр Сергеевич \\ старший преподаватель, Московский \\ авиационный институт (национальный \\ исследовательский университет) \\ verkhovod_a@list.ru
}

Аннотация: В данной работе рассматривается диалогическая речь и ее влияние на развитие коммуникативной компетенции на занятиях иностранным языком. Отмечается, что диалогическая речь на занятиях по иностранному языку представляет собой одну из основных задач формирования коммуникативной компетенции. На данный момент работа над диалогом на иностранном языке является важнейшей методической задачей, что доказывает большое количество статей и исследований, рассмотренных в качестве теоретической основы при написании работы. Анализируется как само понятие диалогической речи, под которой понимается процесс общения, в котором реплики двух и более лиц сменяют друг друга, так и основные ее характеристики. Автором указываются основные виды диалога при изучении иностранного языка, при этом их темы могут быть предусмотрены программой и включать в себя профессиональную проблематику. Делается вывод 0 том, что реплики диалога - это не только вопросы и ответы, точнее их можно описать как связку запроса информации и её получения. В диалогическом общении важно внутреннее принятие оппонентов и ориентация на индивидуальность каждого из них. Поэтому в статье делается акцент на факторы, способствующие положительному обучению диалогической речи, одним из которых являются благоприятные взаимоотношения студента с педагогом. Для педагога важным аспектом диалогического общения со студентом является возможность рассматривать его как равного партнера.

Ключевые слова: иностранный язык, диалогическая речь, диалог, диалогическое общение, коммуникативная компетенция.

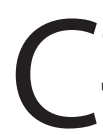

овременное образование переживает новую модернизацию, обусловленную изменяющимися социальными условиями. Этот процесс затрагивает глубокие жизненные установки каждого человека. Для достижения этой цели в рамках высшего образования широко применяются понятия компетентности обучающихся и развитие этих компетенций. Среди многих стратегий обучения преподаватели выбирают те, что смогут максимально эффективно и быстро привести к необходимым итогам. Прежде для улучшения изучения иностранного языка использовались форматы подражания, повторения и запоминания, благотворно влияющие на теоретические знания студентов, но частично лишающие возможности использовать язык как живой инструмент речи. С конца XX века именно коммуникативный подход к обучению позволил переместить акцент на достижение общения на иностранном языке и достиже- ния общих целей в работе с иностранными коллегами у специалистов различных отраслей. Так, английский язык эффективнее изучать с помощью общения на нем, что положительно сказывается на быстроте применения новых знаний у студентов [11].

Ключевые навыки, формирующиеся в процессе обучения английскому языку - письмо, критическое мышление, решение проблем, способность общаться, в рамках формирования коммуникативной компетентности стали моделями коммуникации в различных контекстах.

Касаясь обучения говорению, стоит отметить, что момент организации высказывания внутри разговора и сформированной на этой основе ситуации общения, является важнейшей методической задачей. Именно этот этап обычно вызывает наибольшее количество 
сложностей у обучающихся, требуя внимания к деталям, большого количества времени и усилий с обеих сторон дидактического процесса. Однако, именно этот этап основа для дальнейших успехов, потому что освоение обучающимися такого вида деятельности с усвоением минимального материала дает в дальнейшем надежную мотивацию и достаточное количество базовых знаний для развития речи на иностранном языке. Формируя навыки общения и коммуникативное ядро личности, любой изучающий иностранный язык закладывает твердую основу для выражения любых своих мыслей на другом языке, что помогает самостоятельно решать когнитивные задачи, использовать языковую догадку и выражать мнение относительно новой информации. [2.С.105].

Диалогическая речь на занятиях по иностранному языку представляет собой одну из основных задач формирования коммуникативной компетенции. Лингвистические особенности построения диалогов затрагивали в своих работах такие известные ученые как Л.В. Щерба, С.С. Беркнер, И.Р. Гальперин Г.А. Вейхман, Л.П. Якубинский, Т.Г. Винокур. Проблемой обучения диалогической речи занимались Э.П. Шубин, И.Л. Бим, В.Л. Скалкин, Е.М. Розенбаум, Г.М. Кучинский. На данный момент работа над диалогом на иностранном языке является важнейшей методической задачей, что доказывает большое количество статей и исследований. Учитывая, что вести беседу на изучаемом языке некоторым студентам до сих пор сложно, разработки в этой области должны продолжаться, чтобы решать вопросы и учитывать современные требования, касающиеся общения. [8. С.137].

Сегодня подтвержден тот факт, что говорение и аудирование взаимосвязаны и взаимозависимы. Ведь именно в процессе говорения каждый человек мысленно составляет «конспект» своего будущего высказывания. Но без реализации вслух этого плана невозможно сформировать должный навык общения. Доказано, что продолжительное пассивное слушание искажает слуховые образы, что негативно сказывается на акустико-артикуляционных признаках речи. Предпочтительно выбирать для прослушивания малые объемы текстов, уделяя больше внимания удалению трудностей фонетического, а также лексического и грамматического характеров [4.C.100].

Процесс общения, в котором реплики двух и более лиц сменяют друг друга, называется диалогической речью. Полноценным этот процесс может быть только в случае умения участников вести беседу. Но для того, чтобы диалог с адресатом состоялся, необходимо выстроить его с учетом тематики, характерных особенностей места, где происходит общение, окружающих условий. Характеристики диалога, такие как содержательность (наличие согласий или возражений, вопросов и ответов), разговорность, конструктивная связь всех реплик, а также их взаимосвязанность, и основанная на этом возможность улучшения совместного познания, влияют на результат общения [7.С.216].

Обмен мнениями - это важная мотивация при обучении диалогической речи. Если студент находится внутри речевой ситуации, у него появляется мотив начать процесс общения. Однако, следует учитывать, что речевые ситуации при обучении должны быть максимально реалистичными, естественными, а также профессиональноориентированными. Таким образом, интерес участников диалога будет поддерживаться сам по себе. Подбирать темы необходимо так, чтобы учитывать уровень развития студентов, не ставя перед ними непосильных задач [3].

По мнению некоторых исследователей, в речевых занятиях по иностранному языку огромную роль играет комфортная атмосфера. Для преподавателя одной из важнейших задач в этом отношении является создание ситуаций, в которых акцент будет смещен с его фигуры на равноправное общение самих студентов между собой. Преподаватель в данном случае становится консультантом, наблюдая за процессом, давая полезные советы и высказывая свое мнение по теме [5. С.56].

В диалогическом общении важно внутреннее принятие оппонентов и ориентация на индивидуальность каждого из них. Воспринимая мнения и признавая неповторимость друг друга, можно выстроить успешное общение с большей легкостью. Для педагога важным аспектом диалогического общения со студентом является возможность рассматривать его как равного партнера. Большую роль играет и эмоциональная сторона - преподавателю важно осознавать, как обучаемый относится к нему и насколько хорошо понимает. Выстраивая доброжелательные взаимоотношения с обучающимися, можно сформировать уверенную мотивацию к изучению языка и повлиять на развитие личностных ценностей обучающихся [9.С.226].

Характеристики диалогической речи:

- Двусторонность;

- Прерывистый характер;

- Ситуативность;

- Эллиптичность;

- Спонтанность;

- Межтемность и политематичность;

- Экспрессивность, эмоциональность [6.С.32].

Темы общения на занятиях для современных студентов могут быть предусмотрены программой и включать в себя профессиональную проблематику:

- диалог-беседа, то есть стихийный обмен информацией на основе полученных знаний;

- диалог-разговор на базе увиденной, услышанной, 
прочитанной информации;

- диалог-дискуссия, в ходе которой происходит обоснование собственного мнения с учетом фактов, демонстрируется навык высказываний суждений и построения монолога;

- диалог-расспрос, в ходе которого происходит общение по схеме «вопрос-ответ», строится без подготовки на основе уже знакомых тем [10. С.499].

Невозможно предугадать как будет происходить диалог, следовательно, любая диалогическая речь зависит от речевого поведения партнеров, участвующих в ней. Реплики диалога - это не только вопросы и ответы, точнее можно описать их как связку запроса информации и её получения, но это не единственно возможный ва- риант. В диалогической речи необходимо использовать все возможные связи, позволяющие создать удачный диалог [1. С.73].

Таким образом, диалог - это одно из средств создания коммуникативной компетенции при обучении иностранному языку. Студенты современных вузов сейчас получают образование, базирующееся на основе коммуникативной направленности будущей деятельности. В результате обучения диалогической речи в процессе формирования коммуникативной компетенции, формируется базовый набор умений и навыков, который позволяет строить диалоги профессиональной сложности и использовать иностранный язык на международном уровне.

\section{ЛИТЕРАТУРА}

1. Карагёзян А.С. Совершенствование диалогической речи на занятиях английского языка //Молодежь. Образование. Наука. 2017. Т. 1. № 1-1. С. 72-77.

2. Кузякина Н.А. Обучение монологической и диалогической речи на начальном этапе изучения иностранного языка//Военный научно-практический вестник. 2016. № 1 (4). С. 105-109.

3. Лопатина А.Я. Проблемы обучения диалогической речи на занятиях по иностранному языку в неязыковом вузе//Актуальные проблемы гуманитарных и естественных наук. 2016. № 7-2. С. 95-98.

4. Мартынова 0.В. Некоторые нетрадиционные методы обучения диалогической речи на занятиях в вузе/В сборнике: Методика преподавания иностранных языков и РКИ: традиции и инновации. Сборник материалов IV Международной научно-методической онлайн-конференции. 2019. С. 99-103.

5. Меньш Е.А. Особенности обучения диалогической речи в ввузе в формате Real talk//Высшее образование сегодня. 2017. № 3. С. 56-58.

6. Методика формирования речевой компетенции на иностранном языке: [Электронный ресурс]: Учебное пособие для студентов языковых вузов / Дальневосточный федеральный университет, Школа педагогики; [Автор: Т.И. Скрипникова]. - Электрон. дан. - Владивосток: Дальневосточный федеральный университет, 2018.

7. Прокопенко Ю.А., Карабутова Е.А., Марков А.В. Организация иноязычной грамматики правильной диалогической коммуникации студентов вузов//Современные проблемы науки и образования. 2016. № 2. С. 216.

8. Прокопенко Ю.А. Формирование коммуникативной компетенции обучающихся в процессе обучения диалогу на иностранном языке/ В сборнике: Лингвистическое горизонты. Сборник материалов IV Международной научно-практической конференции. 2016. С. 137-142. С.137-138.

9. Сычева П.А., Ширыхалова А.М. Диалог как средство формирования коммуникативных компетенций на занятиях по иностранному языку/ В сборнике: Язык и культура. Сборник статей XXIX Международной научной конференции. 2019. С. 224-228. С.226.

10. Шалагинова Е.А. Контроль в обучении говорению на неязыковых факультетах//Advanced Science. 2017. № 3. С. 497-505.

11. https://www.grin.com/document/432042

(с) Верховод Александр Сергеевич (verkhovod_a@list.ru).

Журнал «Современная наука: актуальные проблемы теории и практики» 